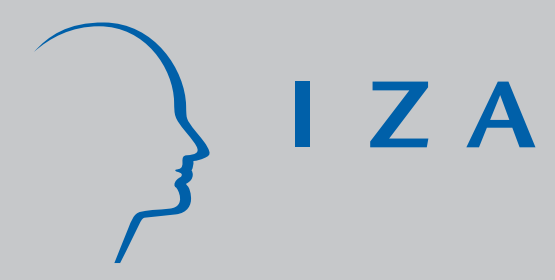

IZA DP No. 1420

The Transition from Welfare to Work and the Role of Potential Labor Income

Hilmar Schneider

Arne Uhlendorff

December 2004 


\title{
The Transition from Welfare to Work and the Role of Potential Labor Income
}

\author{
Hilmar Schneider
}

IZA Bonn

and DIW Berlin

\author{
Arne Uhlendorff \\ DIW Berlin \\ and IZA Bonn
}

Discussion Paper No. 1420

December 2004

\author{
IZA \\ P.O. Box 7240 \\ 53072 Bonn \\ Germany
}

\author{
Phone: +49-228-3894-0 \\ Fax: +49-228-3894-180 \\ Email: iza@iza.org
}

\begin{abstract}
Any opinions expressed here are those of the author(s) and not those of the institute. Research disseminated by IZA may include views on policy, but the institute itself takes no institutional policy positions.
\end{abstract}

The Institute for the Study of Labor (IZA) in Bonn is a local and virtual international research center and a place of communication between science, politics and business. IZA is an independent nonprofit company supported by Deutsche Post World Net. The center is associated with the University of Bonn and offers a stimulating research environment through its research networks, research support, and visitors and doctoral programs. IZA engages in (i) original and internationally competitive research in all fields of labor economics, (ii) development of policy concepts, and (iii) dissemination of research results and concepts to the interested public.

IZA Discussion Papers often represent preliminary work and are circulated to encourage discussion. Citation of such a paper should account for its provisional character. A revised version may be available directly from the author. 


\section{ABSTRACT}

\section{The Transition from Welfare to Work and the Role of Potential Labor Income*}

It is often argued that the high level of welfare claims in Germany causes little incentive for workers with low productivity to seek for a job. We examine the influence of the ratio between estimated potential labor income and the welfare payment level on the probability of leaving social welfare. Using the GSOEP, we estimate a discrete time hazard rate model with competing risks and unobserved heterogeneity. Our results show that the ratio has a positive effect on the probability of leaving social welfare. This effect is especially relevant for households with a potential labor income higher than their welfare payment level.

JEL Classification: I38, J64, C41

Keywords: $\quad$ social welfare, labor supply, duration analysis

Corresponding author:

Hilmar Schneider

IZA Bonn

P.O. Box 7240

53072 Bonn

Germany

Email: schneider@iza.org

\footnotetext{
* We would like to thank Peter Haan, Peter Jensen, Hans-Joachim Rudolph, Katharina Wrohlich, the participants of the SOEP Brown Bag Seminar, the EALE Conference 2004, the IZA Summer School 2004, the IZA Brown Bag Seminar and the GSOEP user conference 2004 for helpful discussions and comments and the German Science Foundation (DFG) for financial support through SPP1169 "Potential for more Flexibility on Heterogeneous Labor Markets".
} 


\section{Introduction}

In Germany, the number of welfare recipients as well as the amount of income support expenditures have been rising almost continuously in the past. In the year 2002, about 2.8 million persons in 1.4 million households received social assistance and the expenditures amount to 25 billion $€{ }^{1}$. The share of the municipalities' revenues spent for the permanent social welfare transfers has been rising from $3.5 \%$ in 1980 to $6.8 \%$ in 2002 (Haustein and Krieger 2004). What is the reason for this large number of welfare recipients? In the economic literature as well as in public debate on the German welfare system the incentive argument plays an important role: If the difference between the level of transfers and potential income from a regular job is too small then picking up a job is not attractive for the individual (see for example Ochel 2003). In this paper, we analyze this hypothesis by estimating the impact of the ratio between potential labor income and the amount of transfer payment on the transition probability from welfare to employment in Germany.

\section{Figure 1: Development of the expenditures for social assistance in Germany}

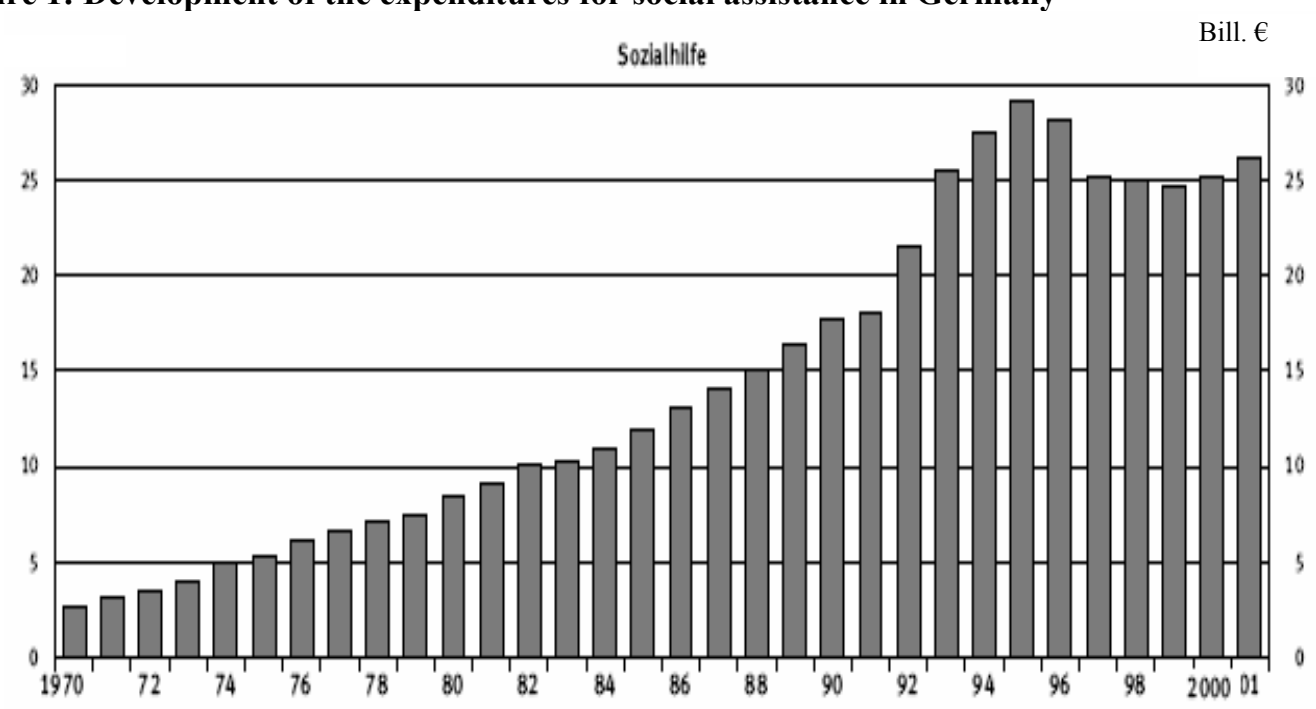

\section{Source: Hahlen (2002)}

The German social assistance is a means-tested transfer program financed by the municipalities. The receipt of transfer payments requires that the household income including other transfer payments like unemployment benefits does not exceed a certain minimum level. In contrast to the unemployment benefits, everybody is principally eligible, irrespective of his or her individual employment history. Although the receipt

This number of welfare recipients refers to permanent transfers, the so-called Hilfe zum Lebensunterhalt, described in detail in section 2. The amount of expenditures refer to permanent transfers and transfers for persons in special circumstances. 
is in principle unlimited, only a minority of households stays on welfare over a longer period of time. Assistance claims expire as soon as alternative income exceeds a certain threshold. This may be due to labor income but could also be due to changes in household formation or the receipt of alternative transfer payments like pensions etc.

Numerous studies exist on the duration of income support spells. Most of them are referring to North America and dealing with women receiving welfare. A typical result says that the probability of leaving welfare is higher for better educated and white persons and declines with the number of (young) children, disabilities, the amount of benefits and the level of regional unemployment (see e.g. Blank 1989, Stewart and Dooley 1999 or Gittleman 2001, a summary is given by Moffitt 1992). For the U.S. Hoynes and Macurdy (1994) find for female heads of households that a decreasing amount of welfare benefits reduces the welfare dependency. Barrett (2000) finds a positive effect of the educational attainment on the welfare exit rate, having a greater impact for women than for men. With a higher educational attainment he assumes a higher offered wage and therefore a higher relative attractiveness of employment. Fortin et al. (2004) use information from a natural experiment in 1989 in the Province of Quebec in Canada. They conclude that a doubling of the amount of social assistance for single men and women aged under 30 significantly increased their individual spell duration.

Hazard rate models are an appropriate tool for the analysis of the duration of welfare receipt. For Germany duration analyses of social assistance usually do not take income variables into account (see for example Voges and Rohwer 1992, Gangl 1998 or Gebauer et al. 2002). Gangl (1998) has shown that it is important to distinguish transitions to employment from alternative transitions like transitions out of the labor market. In descriptive analyses, the social assistance levels are generally compared with the average wage of a special group of employees, for example unskilled workers in manufacturing (e.g. Engels 2001 or Boss 2002). From these descriptive statistics conclusions about the incentives for work for different household types are drawn, but these hypotheses are not tested econometrically. As far as we know, there exist only two studies testing the influence of income variables on the duration of welfare receipt. The study by Riphahn (1999) on basis of the German Socio-Economic Panel study (GSOEP) shows no significant influence of a predicted real net income variable for full-time employed individuals on the exit probability out of income support. However, she does not take the amount of social transfers into account. Wilde (2003) examines the 
difference between social benefits and the average income for unskilled employees on the probability of leaving social welfare using the Low Income Panel and finds no significant effects. Both, Wilde and Riphahn do not distinguish between different transitions in their regression analysis.

In our analysis we use data from the GSOEP. Between 1992 and 2000 retrospective monthly information about social welfare receipt for each month of the previous calendar year is part of the household questionnaire. Spell duration is observed in months, but generated by a continuous time process. Taking into account the discrete time measurement of the underlying data, we estimate a discrete-time proportional hazard rate model with competing risks and risk specific unobserved heterogeneity. We assume that the destination specific hazard rates are constant within each interval and allow for dependent competing risks via a correlation of the random intercepts.

Controlling for several typical covariates the ratio between potential labor income and the welfare level shows a positive effect on the probability of leaving social welfare for work. This effect is especially relevant for households with a potential labor income higher than their social welfare level. In contrast to previous studies, we cannot reject the incentive hypothesis for Germany. The alternative hypothesis, that the higher probability of transition is a consequence of a higher rate of job offers for better educated persons, seems to be of minor relevance: The effect of the ratio keeps significant when controlling for education and the local labor market performance.

Section 2 of this paper gives a short description of the system of social welfare in Germany and its theoretical implications on labor supply. Section 3 provides information on the data and the estimated models. Section 4 presents empirical results and section 5 concludes.

\section{Incentive Effects of Social Assistance in Germany}

The German social assistance (Sozialhilfe) is a means-tested transfer program and consists of two main parts: Permanent transfers to households with low income (Hilfe zum Lebensunterhalt, $H L U$ ) and transfers to persons in special circumstances who need temporary financial support ${ }^{2}$ (Hilfe in besonderen Lebenslagen). In this study we concentrate on the HLU because these payments are principally unlimited and may act as a permanent alternative to a labor income. In the following, the terms welfare and social assistance are used as synonyms and refer to HLU. The receipt of social

\footnotetext{
2 For example, pregnant women or homeless persons searching for a new apartment.
} 
assistance requires that the household income including other transfer payments like unemployment benefits (Arbeitslosengeld and Arbeitslosenhilfe, the latter is also meanstested and principally unlimited) does not exceed a certain minimum level.

In principle, everybody in need may claim for social assistance, while unemployment benefits are only accessible to those who have previously contributed to unemployment insurance for a minimum period within a given time frame. Moreover, the amount of unemployment benefits depends on the income in the previous job, while the amount of social assistance is related to a basic minimum income concept depending on household size and household composition. In addition, the eligibility criteria in case of own income differ between the means-tested unemployment benefits and the social assistance. Therefore, the analysis is restricted to social assistance spells without taking into account spells of the also means-tested Arbeitslosenhilfe. ${ }^{3}$

Welfare benefits consist of basic allowances for every adult household member, housing allowances and one-time payments. The amount for basic allowances differs between the federal states depending on the regional minimal costs of living. In 2003, it ranged between 282 and $297 €$ per month. Children get 50-90 percent depending on age. Expectant mothers, older and disabled persons receive higher basic allowances than "normal" adults. In principle, the amount of social assistance fills the gap between own income and the maximum benefit for the household. Labor income up to $25 \%$ of the basic allowance is not taken into account. Additional income is deducted at an implicit marginal tax rate of $85 \%$ until the deduction exceeds $50 \%$ of the basic allowance. Above this threshold the implicit marginal tax rate is $100 \%$.

The impact of social assistance on work incentives can be described in terms of a very basic utility model for the choice between consumption and leisure (see for example Blundell and MaCurdy 1999 or Moffitt 2002). Assume a utility maximizing individual subject to a non convex budget set. A stylised depiction is given in figure 1 .

If a person is not working at all, he or she will receive social assistance at a level of $V$. If this person works at his or her net market wage rate of $w$ up to $Q$ hours per week, disposable net income will not increase, since earned income is totally deducted from social assistance. Only when the number of hours worked is exceeding $Q$, disposable income will increase with slope $w$. The resulting non convex budget set is expressed in the graph by line B.

Recipients of unemployment benefits are included in our analysis if they are members of households receiving social assistance. 
Figure 2: The impact of social assistance on work incentives for a stylized budget set

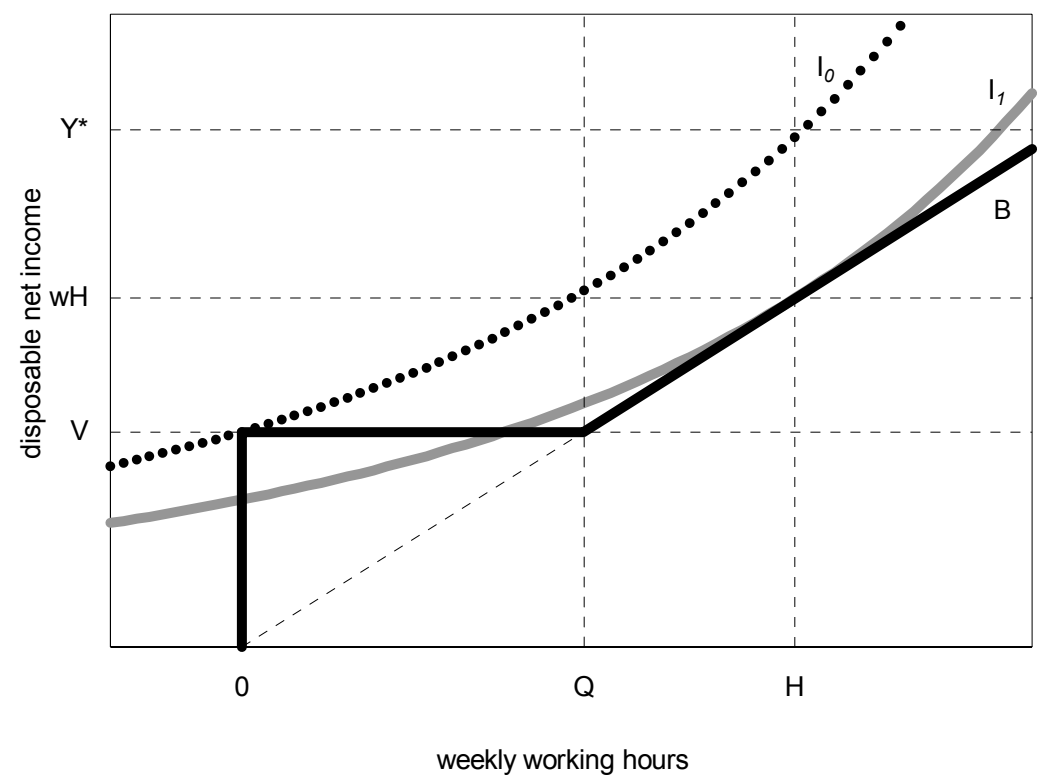

If no social assistance existed, it would be optimal to work $H$ hours per week with a disposable income of $w H$. Beside the budget set, optimal labor supply is a function of individual preferences that are responsible for the shape of the grey indifference curve $\mathrm{I}_{l}$ tangent to the budget line. The utility level associated with $H$ hours of work per week has to be compared to the utility level resulting from not working at all, which is expressed by the dotted indifference curve $\mathrm{I}_{0}$. In the depicted case, not working generates a higher utility level than working. A utility maximizing person would only work $H$ hours per week, if he or she would be able to achieve a disposable income of at least $Y^{*}$, which can also be expressed in terms of an implicit minimum wage rate. Note that $Y^{*}$ in the example given is more than twice as high as $V$.

From this simple static perspective, the individual has perfect information about jobs and is faced with a particular wage. In this framework, periods of welfare receipt and subsequent employment can not be explained. In contrast to that, in a dynamic jobsearch model an individual is not faced with a particular wage but with a particular distribution of wages (e.g. Devine and Kiefer 1991). To leave a welfare program for employment requires an acceptable job offer. The exit rate from welfare to work $\lambda$ depends on the arrival rate of job offers $\omega$ and on the job acceptance rate $\theta$. It can be written as a product of both: $\quad \lambda(t)=\omega(t) * \theta(t)$.

Wage offers are only accepted if they exceed the reservation wage. This reservation wage depends positively on the amount of social benefits. Given that wage offers arrive at a certain frequency and given a level of market (or expected) wage of an individual, it 
is more likely to observe exits from social assistance, the lower the welfare payment. The effect of the level of market wage is theoretically ambiguous. On the one hand, the reservation wage should increase with the expected wage. On the other hand the expected value of a job is higher which should increase the job search intensity. We assume that the positive effects of an increase in the expected wage on the probability of leaving social welfare outweigh the negative effects for the group of welfare recipients in our study. Furthermore we assume that the effect of the difference between the two income sources depends on the relative level of the social benefits. Therefore, households with a lower ratio between potential labor income and the amount of social welfare should have a lower hazard rate from welfare to employment. This is the hypothesis we are going to test in the empirical part of the paper.

In our context, not single persons but households receive transfer payments and one has to decide how to calculate the potential household income. We calculate this income variable assuming one adult household member working full-time (for similar approaches see Riphahn 1999 or Wilde 2003). ${ }^{4}$ An alternative approach could be the assumption of double earner households in the case of partner households. The ratio would be higher for households with two adult persons. However, the simultaneous realization of two employments should be more difficult than the realization of one employment. Therefore at least for short-term utility maximization the assumption of a single earner household seems to be more realistic.

An alternative explanation for a lower exit probability $\lambda$ for households with a lower ratio could be a lack of demand for low skilled workers. The individual market wage strongly depends on the amount of human capital. The ratio between the two income sources varies with the human capital of the household members. Therefore an observed influence of the income ratio on the duration of welfare receipt could be caused by a relatively low arrival rate of job offers for low qualified individuals, even if we hold the job search intensity constant. Theoretically, the influence of a lower arrival rate on the exit probability is ambiguous because the reservation wage depends positively on the arrival rate. But nonetheless, a positive influence of the income ratio could also indicate a lack of demand for low skilled workers. However, different low skilled workers may have different reservation wage levels according to their household related welfare claims. Controlling for skill level may therefore allow for a discrimination between

4 We do not include the costs of working like child care costs in our analysis, but we control for several household characteristics in our empirical model like the existence of children. 
demand effects and incentive effects. In addition to that we control for the local labour market performance.

We assume that the effect of the ratio differs within the range of values. If the expected market wage is clearly below the reservation wage, the probability of an acceptable offer should be small and therefore the search behavior should differ qualitatively from households whose expected market wage is in the same range as the reservation wage or above it. If there exists a range of values corresponding with zero job search activities, an increase of the market wage in this range should not lead to a higher exit probability. Therefore we test the influence of the ratio separately for three ranges of values.

\section{Data, Variables and Methods}

This study uses data from the German Socio-Economic Panel study (GSOEP). The yearly repeated GSOEP started 1984 in West Germany and was extended to include East Germany in 1990. In all panel waves, the head of the household provides information about the household and every household member aged 16 or older provides additional individual information (for details on the GSOEP see Schupp and Wagner 2002). Between 1992 and 2000, retrospective monthly information about social welfare receipt for each month of the previous calendar year is part of the household questionnaire. Excluding households with a head and if existing her partner aged 61 years or older at the beginning of the spell we observe 579 uncensored or right-censored social welfare spells between January 1991 and December 1999, distributed on 455 households. The maximum number of spells of each household is five (one household), 357 households experience one spell of social welfare receipt (Table 1). These spell data are combined with several time-variant and time-invariant household and individual characteristics.

\begin{tabular}{ccc}
\multicolumn{3}{c}{ Table 1: Number of spells per household } \\
\hline number of spells & Freq. & Percent \\
\hline 1 & 357 & 78.46 \\
2 & 76 & 16.70 \\
3 & 19 & 4.18 \\
4 & 2 & 0.44 \\
5 & 1 & 0.22 \\
\hline Total & 455 & 100 \\
\hline
\end{tabular}

In the data there are 386 uncensored and 193 right-censored observations (Table 2). We are interested in the transition from social welfare to a situation with employment income. Therefore we differentiate between transitions to employment (199 cases) and 
alternative transitions (187 cases). A transition to employment is defined as a situation with at least one adult household member (head of the household or her partner) working full-time, both working part-time or one person working part-time in the case of single households subsequent to benefit receipt, at the latest beginning two months after the spell ending. The length of social assistance receipt in our sample ranges from 1 to 90 months. The mean spell length is 13.4 months, spells with a transition to work have an average length of 10.3 months and are on average one month shorter than spells with alternative transitions (11.6 months).

Table 2: Lengths and Destination states

\begin{tabular}{lccc}
\hline Destination state & Freq. & Percent & $\begin{array}{c}\text { Average Length } \\
\text { (Standard deviation) }\end{array}$ \\
\hline Right censored & 193 & 33.3 & $18.2(17.8)$ \\
Transitions to work & 199 & 34.4 & $10.3(10.3)$ \\
Alternative transitions & 187 & 32.3 & $11.6(12.6)$ \\
\hline Total & 579 & 100 & $13.4(14.3)$ \\
\hline
\end{tabular}

Descriptive statistics of the covariables are documented in Table 3. These statistics refer (a) to the status at the beginning of a welfare spell $(n=579)$ and (b) to the monthly status (every month one observation, $\mathrm{n}=7752$ ). Spell observations mostly ends within one year $(71 \%)$, afterwards the number of spells ending decreases constantly. About $15 \%$ of the whole sample end in the second year of observation, $7 \%$ in the third and $3 \%$ in the fourth year, $4 \%$ last for more than four years. These proportions refer to all spells, independent of the censor status. To control for the economic situation we include time dummies for each year of observation. The proportion of spells beginning in different years ranges from $4 \%$ in 1991 up to $16 \%$ in $1994 .{ }^{5}$ Disproportional numbers of welfare spells start in January or end in December. Therefore we include January and December dummies in our analyses. Around one quarter of the observed households live in East Germany. The mean of the local unemployment rate is $11.6 \%$, whereby the values range from 3.7 to 21.7 referring to federal states and yearly averages ${ }^{6}$. Nearly half of the households are single households, $38 \%$ female and $10 \%$ male singles. The head of a household or her partner is aged older than 50 years in $12 \%$ of the observed spells and in $32 \%$ a foreign head or partner is living in the household. In every tenth

5 One has to be careful with interpretations of these descriptive statistics. For example the increase in social assistance spells beginning in 1999 can be at least partly explained by the new sub sample F (Innovation Sample) of the GSOEP in 2000. Due to this new sample F the sample size of the GSOEP has increased substantially.

6 The unemployment rate is defined as the quotient between unemployed registered persons and persons in civilian employment. The rates are taken from the German Statistical Yearbook (Statistisches Jahrbuch 2001) 
household the head or his partner is handicapped, which means that at least one of these persons answers the question whether he or she is officially registered as having a reduced capacity for work or of being severely disabled with yes. Children aged 6 years and younger live in $40 \%$ per cent of the households, children between 6 and 18 in 36\%. In nearly all households the head or her partner holds at least a compulsory school degree $(93 \%)$ while only in about two thirds of all households at least one of these persons has finished vocational training $(60 \%)$. The statistics based on the observed months differ from the reported statistics due to the higher weight of longer spells.

Table 3: Descriptive statistics: (a) each spell one observation (household characteristics in the first month), (b) each month one observation

\begin{tabular}{|c|c|c|}
\hline Variable & $\begin{array}{c}\text { (a) } \\
\text { Mean / Share } \\
\text { (standard deviation) }\end{array}$ & $\begin{array}{c}\text { (b) } \\
\text { Mean / Share } \\
\text { (standard deviation) }\end{array}$ \\
\hline \multicolumn{3}{|l|}{ End/ Time of Observation } \\
\hline 1 year & 0.71 & 0.61 \\
\hline 2 years & 0.15 & 0.20 \\
\hline 3 years & 0.07 & 0.09 \\
\hline 4 years & 0.03 & 0.05 \\
\hline$>4$ years & 0.04 & 0.05 \\
\hline \multicolumn{3}{|l|}{ Year of Observation } \\
\hline 1991 & 0.04 & 0.01 \\
\hline 1992 & 0.07 & 0.05 \\
\hline 1993 & 0.11 & 0.09 \\
\hline 1994 & 0.16 & 0.12 \\
\hline 1995 & 0.12 & 0.13 \\
\hline 1996 & 0.10 & 0.13 \\
\hline 1997 & 0.13 & 0.15 \\
\hline 1998 & 0.12 & 0.16 \\
\hline 1999 & 0.15 & 0.15 \\
\hline December dummy & 0.07 & 0.10 \\
\hline January dummy & 0.34 & 0.07 \\
\hline East Germany & 0.27 & 0.21 \\
\hline Local unemployment rate & $11.62(4.12)$ & $11.65(4.09)$ \\
\hline At least one adult household member with school graduation & 0.93 & 0.90 \\
\hline At least one adult household member with vocational training & 0.60 & 0.56 \\
\hline No partner household (female) & 0.38 & 0.43 \\
\hline No partner household (male) & 0.10 & 0.08 \\
\hline Adult household member aged $>50$ & 0.12 & 0.20 \\
\hline Non German adult household member & 0.32 & 0.33 \\
\hline Children aged 6 and younger & 0.40 & 0.43 \\
\hline Children aged between 6 and 18 & 0.36 & 0.34 \\
\hline Handicapped adult household member & 0.10 & 0.13 \\
\hline Ratio between potential net income and benefit amount & $1.39(0.50)$ & $1.33(0.44)$ \\
\hline Sample Size & 579 & 7752 \\
\hline
\end{tabular}

Before discussing the ratio and the difference between the potential household income in case of one adult person working full-time and the social assistance amount, we describe the estimating and calculating procedures of these two income sources separately in the following. 


\subsection{Estimation of Potential Net-Income}

In a first step we estimate potential gross market wages of all heads of the household and as the case may be of their partner. We cannot observe their wages directly because most of the individuals in our data set are not working while receiving social assistance. Therefore we estimate the potential wages using all individuals in working age. Whether or not we observe wages depends on an individual's participation decision. Due to this self-selection we cannot assume the sample of workers to be a random sample of all potential working individuals and we have to account for the sample selection problem.

The sample selection model we apply, also referred to as the type II Tobit model (e.g. Wooldridge 2002), consists of a log-linear wage equation

$$
\log w_{i}=X_{1 i} \beta_{1}+\varepsilon_{1 i}
$$

with $X_{l i}$ as a vector containing exogenous characteristics and $w_{i}$ as person's $i$ wage and an equation describing the binary choice to work or not to work and therefore determining the sample selection

$$
z_{i}^{*}=X_{2 i} \beta_{2}+\varepsilon_{2 i} .
$$

We observe wages according to the rule:

$$
\begin{aligned}
& w_{i}=w_{i}^{*}, z_{i}=1 \text { if } z_{i i}^{*}>0 \\
& w_{i} \text { not observed, } z_{i}=0 \text { if } z_{i i}^{*} \leq 0
\end{aligned}
$$

whereby $z_{i}$ indicates working or not working and this depends on the characteristics $X_{2 i}$. One can estimate the wage equation consistently assuming that the two error components of the two equations follow a bivariate normal distribution. The expected value of $\log$ (wage) for individuals not working corresponds to:

$$
E\left\{\log w_{i} \mid z_{i}=0\right\}=X_{1 i} \beta_{1}-\sigma_{12} \frac{\phi\left(X_{2 i} \beta_{2}\right)}{1-\Phi\left(X_{2 i} \beta_{2}\right)}
$$

We estimate separated models for East and West Germany and for men and women with a pooled sample using the GSOEP waves from $1991-1999^{7}$. The estimation results are reported in tables A1-A2. We control for the year and the region. Education, measured in years, age and firm specific capital, measured in years being employed at the actual employer, have significantly positive influence on the wage per hour, while the squared age and the squared firm specific capital have a significantly negative

We excluded individuals working short time (Kurzarbeit), doing a vocational training, military or community service. In addition to that we exclude persons aged 60 and older. 
impact. Foreigners have lower wages in both regions and the absence from the labor market in years, accounting for the previous five years, have a negative impact on the wage. While the squared absence from the labor market influences the wage positively in East Germany, the effect in West Germany is insignificant.

Using these estimation results, we calculate a potential monthly full-time gross wage for each head of household and her partner. Calculating the potential net income, we assume that in the case of a partner household the person with the higher income would work and we account for income taxes, social security contributions, child and housing allowance.

\subsection{Social Assistance}

The amount of social assistance was not asked in all waves of the GSOEP. Furthermore, in the years the amount of social assistance was part of the questionnaire, the current amount but not the monthly amount during the previous year was asked. Therefore we can observe the monthly receipt as a binary variable but not the corresponding amount of social assistance.

Instead of direct observation we calculate the maximum of social assistance. This is the permanent income, including other transfers, a household staying on welfare would receive permanently. As described above this amount depends on the number and the age of household members and varies by the region and the year of receipt. We use the average yearly individual basic allowances for East and West Germany to calculate the basic allowance for each household member and add them up. Moreover we consider the one-time payments by using the same method as Breuer and Engels (2003) or Boss (2002): We calculate $16 \%$ of the individual basic allowance for the head of household, $17 \%$ for the partner and $20 \%$ for each child. In addition to that we take an allowance for housing depending on the household size into account.

\subsection{Ratio between Employment Income and Social Assistance}

We calculate the ratio between the potential household net income in case of one person working fulltime and the amount of transfer payment. The empirical distribution of this variable in the first month of each spell is plotted in Figure 3. The median is 1.26 , i.e. for about half the sample expected income does not exceed their welfare benefits by more than $25 \%$. This indicates that the incentives to search for a job may be low for a lot of individuals being on social welfare. The median of the distribution corresponding to all observed months is lower with 1.21 (see appendix, Figure A1), which reflects the higher weight of longer spells in the distributions of all month- 
observations. This indicates that a lower income ratio may go along with a longer stay in the social assistance. ${ }^{8}$ We interact the ratio with three dummy variables and thereby split the ratio in three parts:

- Ratio 1: takes on the ratio value if the ratio is below 1

(25\% of all months)

- Ratio 2: takes on the ratio value if the ratio is between 1 and 1.5 (45\% of all months)

- Ratio 3: takes on the ratio value if the ratio is above 1.5 ( $29 \%$ of all months)

One could argue that the difference between potential household net income could never be negative and therefore the ratio could never be lower one, because these households would receive supplementary transfer payments (see for example Wilde 2003). Nevertheless we use ratios lower than one in our analysis, because we estimate the mean of a wage distribution an individual is faced with and not a deterministic wage. It is possible that a person receives a job offer with a wage resulting in a higher net household income than social assistance, although the mean of his wage distribution is lower than the benefits. A ratio lower than one indicates a relatively low probability of such an offer. Censoring the ratio variable would lead to a loss of information indicating the probability of acceptable offers.

In addition to that one can observe households who are eligible for social assistance but do non take it up. This (non-) take-up behavior depends among others on the expected benefit amount (see e.g. Riphahn 2001): The probability of take-up rises with the potential amount of transfer payments. Because we are interested in the leaving processes of social assistance, the ratio between the two separate income sources and not the combination of the different income sources is the relevant variable.

In Figure 4 we plot the corresponding income ratio of the single earner households not receiving social welfare in the GSOEP. The median of this distribution is with 1.89 clearly higher than the one of the estimated ratio of households receiving social welfare. $2.7 \%$ of these households have a ratio lower than one, i.e. they would have a higher income receiving social welfare instead of one person working full time. On the one hand this could be explained with application and stigma costs (see e.g. Kayser and Frick 2001 or Riphahn 2001). On the other hand we only account for employment income and do not consider other income. Therefore the net household income used for the calculation is the lower bound of the real net income.

8 Separated histograms for single and couple households are presented in the appendix (Figures A2 and A3). 
Fig. 3: Histogram: Ratio between potential net income and the amount of social assistance, first month of welfare spell $(n=579)$

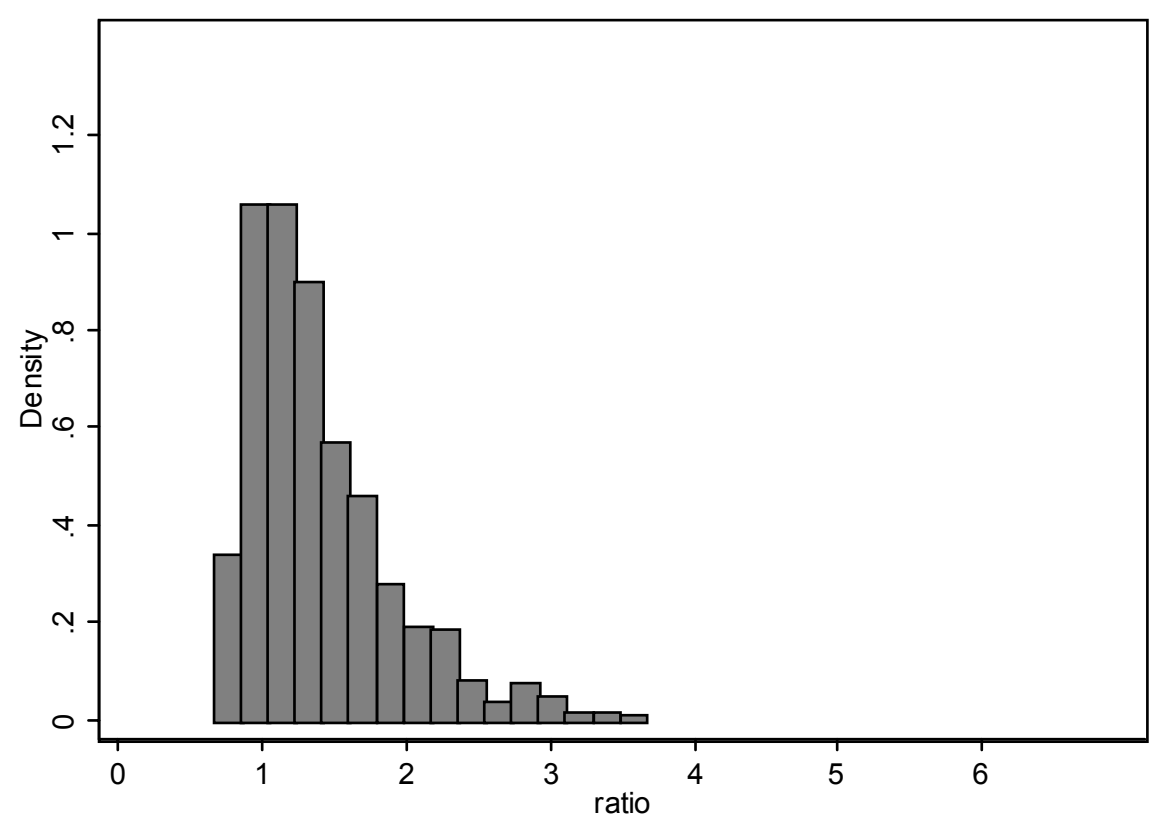

Fig. 4: Histogram: Ratio between net employment income and the potential amount of social assistance for single earner households in the GSOEP in 1999, unweighted, $(n=2411)$

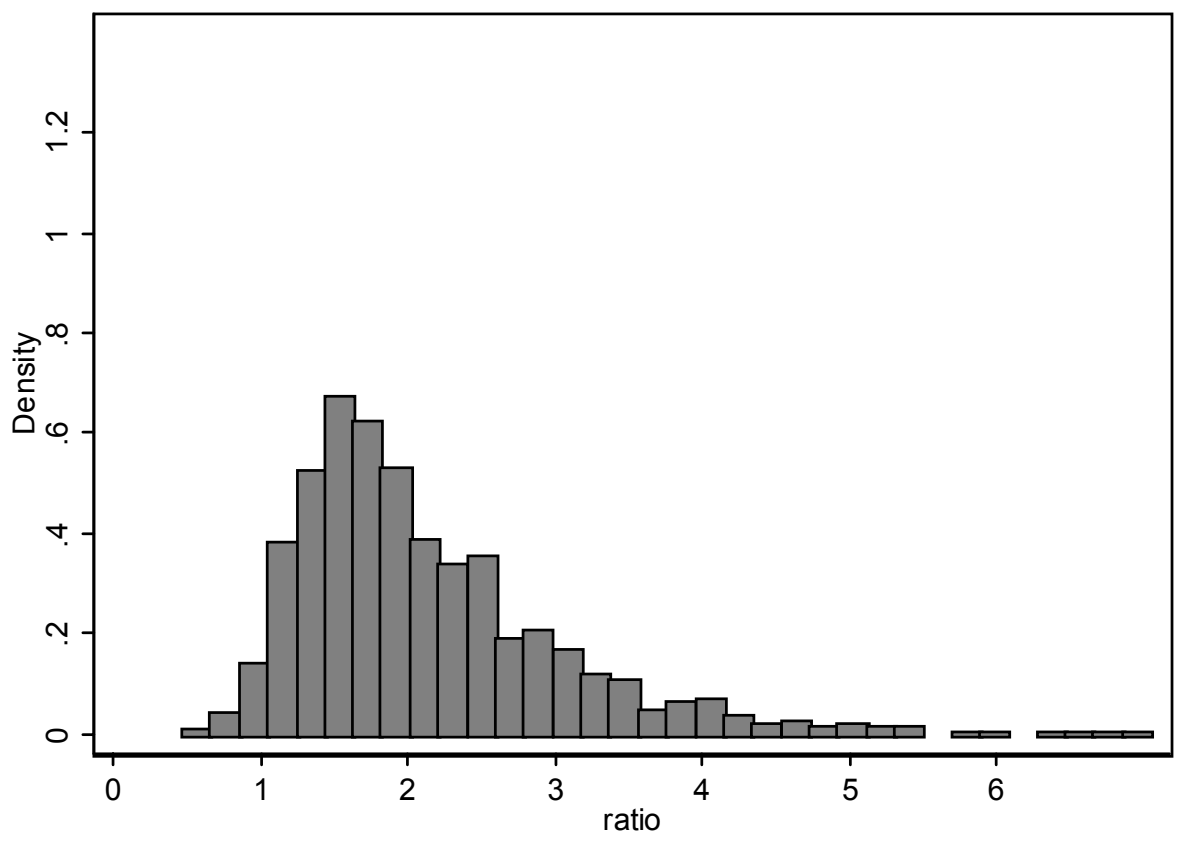

\subsection{Model Specification}

The process of leaving social welfare in favor of labor income can appropriately be modeled by a transition rate approach. According to the type of data being used here, a discrete hazard rate model has to be applied (see for example Han and Hausman 1990, Jenkins 2004, Meyer 1990, Sueyoshi 1992, Narendranathan and Stewart 1993a). The duration of welfare receipt is generated by a continuous time process, but observed or 
grouped in monthly intervals. Two potential destination states $q$ are considered reflecting transitions to employment $(q=1)$ and alternative transitions like for example other transfer programs or marriage $(q=2)$. The hazard rate is defined as the limit of the conditional probability for the ending of a spell in interval $[t ; t+\Delta t[$ given that no transition occurred before the start of this interval:

$$
\lambda(t)=\lim _{\Delta t \rightarrow 0} \frac{P(t \leq T<t+\Delta t \mid T \geq t)}{\Delta t}
$$

where $T$ denotes the length of a spell. $T$ is assumed to be a continuous, non-negative random variable. We assume proportional transition rates with covariates causing proportional shifts of a so-called baseline transition rate and interval constant covariates. The hazard rate $\lambda(t \mid x(t))$ corresponds to the sum of the two transition rates 9

$$
\lambda(t \mid x(t))=\sum_{q=1}^{2} \lambda_{q}(t \mid x(t))
$$

with the transition probability to destination state $q$ corresponding to

$$
\lambda_{q}(t \mid x(t))=\lambda_{0 q}(t) \exp \left(x(t) \beta_{q}+\eta_{q}\right) \text { with }\left(\eta_{1}, \eta_{2}\right) \sim N\left(0,0, \sigma_{1}^{2}, \sigma_{2}^{2}, \rho\right) .
$$

$\lambda_{o q}(t)$ denotes the destination specific baseline transition rate, $x(t)$ a time variant row vector of covariates, $\beta_{q}$ a column vector of parameters and $\eta_{q}$ a time invariant individual and destination specific error term, representing the joint influence of unobserved heterogeneity. We assume these error terms or random intercepts to be bivariate normally distributed with expected values 0 , which allows for dependent competing risks.

Discrete-time measurement leads to the simplifying consequence that instead of continuous levels of $\lambda_{o q}(t)$ and $x(t)$ only their interval specific mean levels have to be taken into account. Assumed that the time axis is divided into intervals of unit length, a given spell consists of a number of $k$ intervals, in the following referred to as subspells. The $j$ th subspell covers a range from $t=j-1$ to $t+1$, but excluding $t+1$. The interval specific means of $\lambda_{o q}(t)$ and $x(t)$ are then denoted as $\lambda_{o q}(j)$ and $x_{j}$.

For the survivor function this implies:

$$
S(j)=\exp \left(-\sum_{q=1}^{2} \sum_{k=1}^{j} \exp \left(x_{q k} \beta_{k}+\gamma_{q k}+\eta_{q}\right)\right) \text { with } \gamma_{q k}=\ln \left(\int_{t_{k-1}}^{t_{k}} \lambda_{0 q}(\tau) d \tau\right)
$$

$9 \quad$ In principle destination specific covariables $x_{q}$ are allowed but not considered here. For the general model with destination specific covariables see appendix. 
The survivor function $S(j)$ describes the probability that a spell lasts at least $j$ intervals. The $\gamma$ parameters are capturing the duration dependence of the baseline transition function. They may be interpreted as an interval specific mean of the baseline transition rate, which is equivalent to an interval specific constant baseline transition rate.

Following from this, the probability $f$ of a transition to state $r$ at a given interval $j$ is given by the difference of two survivor functions multiplied by the share of the riskspecific transition rate at interval $j$ related to the hazard rate at interval $j$.

$$
f_{r}(j)=\frac{\exp \left(x_{r j} \beta_{r}+\gamma_{r j}+\eta_{r}\right)}{\sum_{q=1}^{2} \exp \left(x_{q j} \beta_{q}+\gamma_{q j}+\eta_{q}\right)}[S(j-1)-S(j)]
$$

The likelihood contribution of a spell corresponds to

$$
L\left(\beta, \gamma, \eta_{1}, \eta_{2}\right)=\frac{\exp \left(x_{1 j} \beta_{1}+\gamma_{1 j}+\eta_{1}\right)^{c_{1}} \exp \left(x_{2 j} \beta_{2}+\gamma_{2 j}+\eta_{2}\right)^{c_{2}}}{\sum_{q=1}^{2} \exp \left(x_{q j} \beta_{q}+\gamma_{q j}+\eta_{q}\right)}[c S(j-1)-(2 c-1) S(j)]
$$

whereby $c_{1}=1$ and $c_{2}=1$ indicate a transition to risk 1 and risk 2 in interval $j$, respectively, and $c$ corresponds to the maximum of $c_{1}$ and $c_{2}$. It implies that rightcensored spells are assumed to be censored at the end of the related interval, but that transitions may occur somewhere between $j-1$ and $j$. The likelihood contribution is not separable into destination-specific components as suggested by Narendranathan and Stewart (1993b) because we do not assume that transitions can only occur at the interval boundaries (see Roed and Nordberg 2003 or Jenkins 2004 for similar approaches). Therefore we can not estimate destination specific models separately, even in a model without unobserved heterogeneity. In the following, we will refer to this as a piecewise exponential model and a random effects piecewise exponential model, respectively.

\section{Empirical Results}

We estimate discrete time hazard rate models with and without unobserved heterogeneity. The coefficients can be interpreted with respect to the underlying continuous time proportional hazard rate. We estimate our models with and without splitting the income ratio into three parts, the results are reported in Table 4 and Table

10 The corresponding likelihood is solved by applying Gauss-Hermite quadrature. 
A3 respectively. The inclusion of unobserved heterogeneity does not significantly improve the model fit. ${ }^{11}$

We created three variables representing the effect of the ratio between estimated potential labor income and welfare payment level: The first for ratios lower and equal 1, the second for ratios from 1 to 1.5 and the third for ratios above $1.5 .^{12}$ In both models with and without unobserved heterogeneity the coefficients of the latter two variables are significantly positive, while the coefficient of the first is positive but not significantly different from zero. An increase in the ratio seems to be more relevant if the potential labor income exceeds the social assistance level (see Table 4). Estimating the model with one ratio variable leads to a weakly significantly positive influence (at the 10 percent level, see Table A3).

The coefficient of the income ratio for a ratio between 1 and 1.5 indicates that a 0.1 higher ratio goes along with a $10 \%$ higher probability of an exit to employment, while a 0.1 higher ratio for ratios above 1.5 leads to $7 \%$ higher probability of a transition to employment. However, the difference between the two coefficients is not significant and therefore a further interpretation is not useful. Assuming households with the same welfare level, a difference in the income ratio of 0.1 stands for a difference in estimated labor income by $10 \%$ of the social welfare level. For alternative transitions, these income variables have no significant influence. Our results confirm our predictions: Given a level of social welfare payment it is more likely to observe exits from social assistance to employment, the higher an individuals (net) market wage is. This is especially the case for households with an expected labor income higher than the social assistance level. Only if the household is able to improve its income through employment, the difference between the two income sources matter. The hazard rates of two types of households with income ratios of 0.5 and 2 are plotted exemplarily in Figure A4 in the appendix. The hazard rates are calculated for average households, differing only in their income ratios. The estimated hazard rate of the household with an income ratio of 2 is 2.3 times higher than the one of the household with the lower income ratio.

11 Interpretation of the $t$-values of the variance parameters is not useful since $\ln$ (variance) being 0 means that the variance itself is equal to 1 . Testing for the variance being 0 would mean to test $\ln$ (variance) equalling minus infinity, which is not feasible.

12 The ratio takes on the value 1 if the potential labor income equals the welfare payment level and the value 1.5 if the potential labor exceeds the social welfare payments by $50 \%$. 
The relevance of incentive effects is stressed by the fact that skill indicators and the local unemployment rate turn out to be insignificant. ${ }^{13}$ The other relevant covariates for the transition from welfare to work are quite similar, independent of the model we estimate. Households with a head being single have a significant lower probability of leaving social welfare via employment than partner households. This effect is especially strong for women. Households with the head or her partner being older than 50 years have a lower exit probability than younger households. The presence of young children has no significant effect on the duration of welfare receipt, while older children between 6 and 18 reduce the duration of social welfare receipt. Households in East Germany exit faster to employment, which is a surprising result because of the relatively bad economic performance of East Germany. One possible (ad-hoc) explanation may be a relatively large number of transitions into public financed jobs for unemployed persons in East Germany, but this has to be checked empirically. The existence of a handicapped adult household member seems to have no influence on the transition probability. Moreover the nationality of adult household members does not affect the exit probability of households. In addition to that the existence of an adult person with vocational or a school graduation has no influence on the probability of exiting social welfare. This result is similar to that of Riphahn $(1999)^{14}$ who identifies only a significant effect for a university degree but not for vocational training while Wilde (2003) and Gangl (1998) identify positive effects of a vocational training. The local unemployment rate has a negative but insignificant effect on the welfare duration.

In contrast to the transitions to work, the income variables have no significant influence on the probability of alternative transitions, reported in the rows "Alternative Transitions" in the Tables 4 and A3. This is an expected result and shows the importance to differentiate between alternative risks when examining the transition from welfare to work and the role of estimated labor income.

Our results confirm our predictions: Given a level of social welfare payment it is more likely to observe exits from social assistance to work, the higher an individuals (net) market wage is. In contrast to other studies like Riphahn (1999) or Wilde (2003)

13 One could argue that the local unemployment rate is endogenous because the transitions from social assistance to work directly influence the rate of unemployed persons. However, the results do not change leaving out the unemployment rate.

14 Riphahn estimates two sorts of models using different covariables: Duration models with continuous time and household as well as individual characteristics on the one hand and duration models with discrete time and household characteristics with an additional estimated income variable on the other hand. We refer to both model categories. 
we estimate a positive effect of the potential net labor income on the transition probability and this effect seems to be more relevant for households with a potential market wage above their social assistance level.

In the GSOEP the net household income is asked every year. In Figure 5 both, the predicted and the realized income ratios of the households leaving social welfare for work are plotted. The mean of the realized ratio distribution is with 1.43 slightly above the estimated ratio with a mean of 1.36 . Around $20 \%$ of our households have a lower income after leaving social welfare. This observation is in line with the results of Wilde (2003) who observes $25 \%$ of the households realizing a lower income. There exist several possible explanations for this observation. Because of stigma costs it could be rational for some households to accept an income loss, there could exist measurement errors in the income variable or some households could earn additional money with unobservable illegal employment. However, most of our observation have a significantly higher income after leaving social welfare for work. In Figure 6 our calculated and the realized ratios are plotted together. One can see that both variables correlate not perfectly but clearly positively.

Fig. 5: Histogram: Ratio between potential net income and the amount of social assistance, (a) predicted $(n=199)$ and $(b)$ realized $(n=150)^{15}$
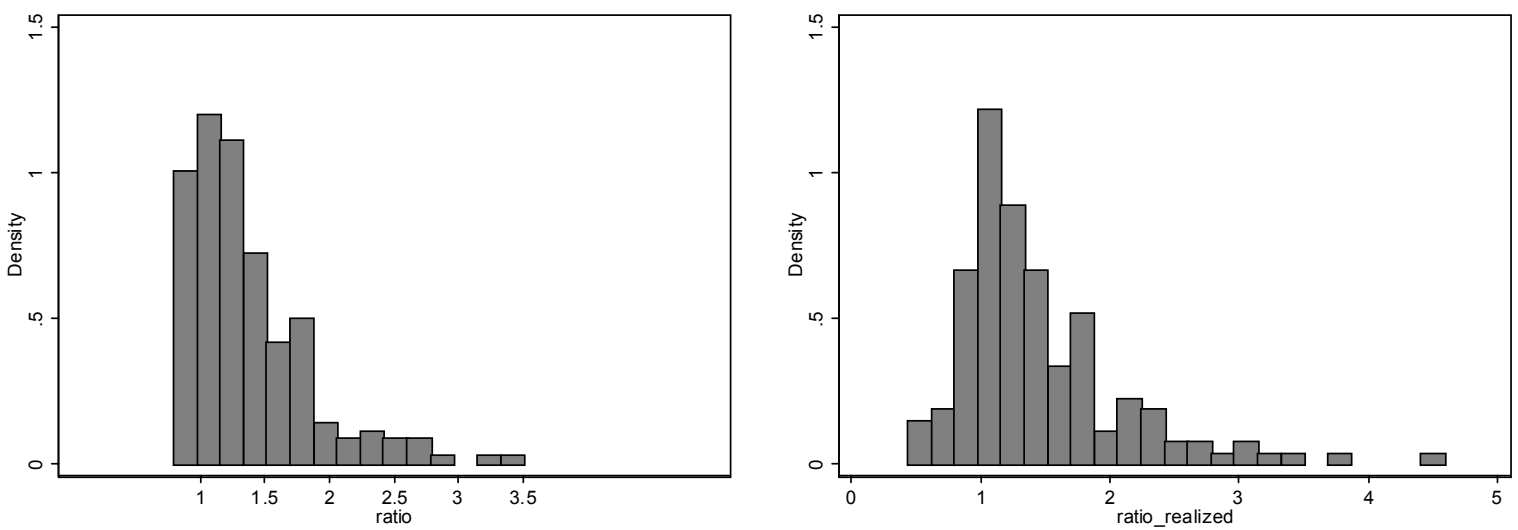

15 In 49 cases the income variable is missing or the household started to receive social assistance again. 
Fig. 6: Scatterplot of the predicted and the realized ratio $(n=150)$

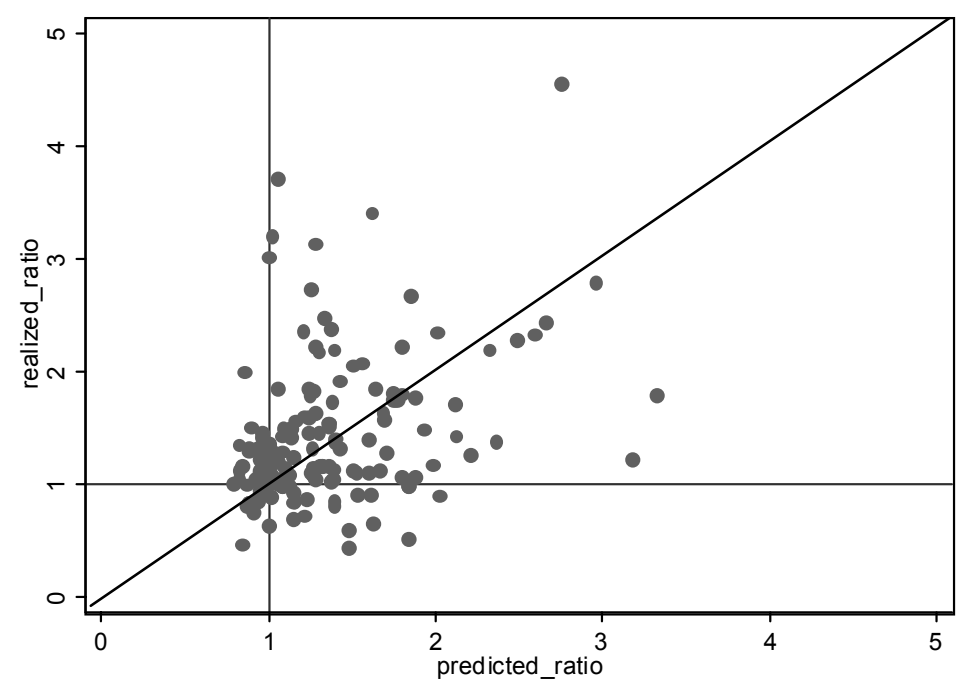

\section{Conclusion}

The aim of the study was to estimate the influence of the ratio between estimated potential labor income and the welfare payment level on the probability of a transition from social welfare to work. We use data from the GSOEP waves 1992-2000 including information about spell duration of households receiving social welfare and the monthly employment status of the household members. The potential net labor income is estimated with standard wage equations accounting for sample selection and applying a simple tax function. We estimate a discrete-time proportional hazard rate model with competing risks and risk specific unobserved heterogeneity.

The ratio between potential labor income and the welfare level shows a positive effect on the probability of a transition to employment for households whose potential labor income exceeds their welfare payment level. Our results are contrary to previous studies dealing with the determinants of welfare spell duration in Germany: We identify an effect of the income ratio according to the standard theoretical predictions. This "new" result derives from a simultaneous consideration of both sources of income, the net household labor income and the social welfare level, and additionally from a differentiation between transitions to work and alternative transitions.

The alternative explanation for low skilled workers being more likely to be hit by long term unemployment according to a lower job offer arrival rate for low skilled employment turns out to be of minor relevance. Contrary to the ratio indicators, skill indicators are far from being significant. Obviously, the explanatory power of skills is outweighed by incentive effects. 
Our results cannot lead to the conclusion that the social assistance level in Germany is too high, because the amount of social assistance is related to a basic minimum income concept. A reduction of the social assistance level is not the only way to overcome incentive problems of a transfer program, there exist other possible solutions like for example workfare. 
Table 4: Discrete-time proportional hazard rate models

\begin{tabular}{|c|c|c|c|c|c|c|c|c|}
\hline \multirow[b]{3}{*}{ Variable } & \multicolumn{4}{|c|}{ Piecewise exponential model } & \multicolumn{4}{|c|}{ Random effects piecewise exponential model } \\
\hline & \multicolumn{2}{|c|}{$\begin{array}{l}\text { Transitions to } \\
\text { Employment }\end{array}$} & \multicolumn{2}{|c|}{ Alternative Transitions } & \multicolumn{2}{|c|}{$\begin{array}{l}\text { Transitions to } \\
\text { Employment }\end{array}$} & \multicolumn{2}{|c|}{ Alternative Transitions } \\
\hline & Coefficient & t-value & Coef. & t-value & Coefficient & t-value & Coef. & t-value \\
\hline 2 years & $-0.41 *$ & -1.84 & $-0.57 * *$ & 2.55 & -0.37 & -1.35 & -0.41 & -1.14 \\
\hline 3 years & -0.31 & -0.94 & $-0.655 *$ & 1.92 & -0.27 & -0.64 & -0.40 & -0.72 \\
\hline 4 years & -0.79 & -1.52 & -0.75 & 1.61 & -0.74 & -1.21 & -0.45 & -0.65 \\
\hline 5 and more years & $-1.30 *$ & -1.79 & -0.97 & 1.60 & -1.25 & -1.51 & -0.63 & -0.74 \\
\hline \multicolumn{9}{|l|}{$\underline{\text { Year of observation }}$} \\
\hline 1992 & -0.41 & -0.77 & 0.25 & 0.46 & -0.42 & -0.78 & 0.21 & 0.36 \\
\hline 1993 & -0.12 & -0.25 & 0.31 & 0.58 & -0.13 & -0.25 & 0.26 & 0.47 \\
\hline 1994 & 0.02 & 0.05 & 0.41 & 0.80 & 0.03 & 0.06 & 0.42 & 0.76 \\
\hline 1995 & -0.29 & -0.59 & 0.10 & 0.19 & -0.28 & -0.57 & 0.10 & 0.18 \\
\hline 1996 & -0.48 & -0.93 & 0.41 & 0.78 & -0.48 & -0.92 & 0.40 & 0.70 \\
\hline 1997 & -0.25 & -0.48 & 0.28 & 0.51 & -0.25 & -0.48 & 0.23 & 0.39 \\
\hline 1998 & 0.14 & 0.28 & 0.28 & 0.51 & 0.14 & 0.29 & 0.27 & 0.46 \\
\hline 1999 & $-1.22 * *$ & -2.22 & -0.75 & -1.31 & $-1.22 * *$ & -2.22 & -0.81 & -1.32 \\
\hline December dummy & $2.32 * * *$ & 16.08 & $3.03 * * *$ & 19.35 & $2.33 * * *$ & 15.15 & $3.08 * * *$ & 15.99 \\
\hline January dummy & $-1.44 * *$ & -2.01 & -0.55 & -0.93 & $-1.44 * *$ & -2.01 & -0.52 & -0.87 \\
\hline East Germany & $0.77 * *$ & 2.31 & $0.73 * *$ & 2.03 & $0.78 * *$ & 2.28 & 0.79 & 1.97 \\
\hline Local unemployment rate & -0.05 & -1.40 & -0.05 & -1.38 & -0.05 & -1.38 & -0.05 & -1.22 \\
\hline $\begin{array}{l}\text { At least one adult household member } \\
\text { with vocational training }\end{array}$ & 0.20 & 1.05 & -0.17 & -0.91 & 0.20 & 1.03 & -0.17 & -0.85 \\
\hline $\begin{array}{l}\text { At least one adult household member } \\
\text { with school graduation }\end{array}$ & 0.16 & 0.43 & 0.26 & 0.84 & 0.17 & 0.44 & 0.29 & 0.84 \\
\hline No partner household (female) & $-0.68 * * *$ & -3.78 & 0.15 & 0.86 & $-0.68 * * *$ & -3.67 & 0.18 & 0.80 \\
\hline No partner household (male) & $-0.60 *$ & -1.73 & 0.13 & 0.42 & -0.61 & -1.71 & 0.15 & 0.40 \\
\hline Adult household member aged $>50$ & $-0.83 * * *$ & -2.89 & -0.42 & -1.64 & $-0.84 * * *$ & -2.85 & -0.49 & -1.60 \\
\hline Children aged 6 and younger & -0.26 & -1.58 & -0.14 & -0.75 & -0.27 & -1.56 & -0.15 & -0.73 \\
\hline Children aged between 6 and 18 & $0.46 * *$ & 2.53 & 0.08 & 0.38 & $0.46 * *$ & 2.49 & 0.08 & 0.36 \\
\hline Non German adult household member & -0.23 & -1.24 & 0.17 & 0.93 & -0.23 & -1.22 & 0.24 & 0.96 \\
\hline Handicapped adult household member & -0.15 & -0.57 & -0.02 & -0.07 & -0.16 & -0.58 & -0.04 & -0.14 \\
\hline Income Ratio $<1$ & 0.92 & 1.61 & 0.56 & 1.01 & 0.91 & 1.59 & 0.50 & 0.42 \\
\hline $1<=$ Income Ratio $<1.5$ & $0.93 * *$ & 2.23 & 0.33 & 0.79 & $0.93 * *$ & 2.20 & 0.30 & 0.51 \\
\hline $1.5<=$ Income Ratio & $0.64 * *$ & 2.31 & 0.41 & 1.49 & $0.64 * *$ & 2.29 & 0.42 & 0.18 \\
\hline Constant & $-4.28 * * *$ & -5.35 & -4.94 & -6.06 & $-4.29 * * *$ & -5.29 & $-5.11 * * *$ & -5.12 \\
\hline $\operatorname{Ln}\left(\sigma^{2}\right)$ & - & - & - & - & -4.33 & -0.08 & -0.49 & -0.38 \\
\hline $\operatorname{COV}\left(\eta_{1}, \eta_{2}\right)$ & - & & & & -0 & & & \\
\hline Log Likelihood & & & 4.42 & & & & 4.24 & \\
\hline
\end{tabular}

579 spells, 7752 months, $*$ significant at the 10 percent level, ** at the 5 percent level, *** at the 1 percent level. For missing values concerning the handicap and vocational training variables we included additional dummies. Their insignificant coefficients are not reported here. 


\section{References}

Barrett, Garry F. (2000): The effect of educational attainment on welfare dependence: Evidence from Canada, Journal of Public Economics, 77, 209-232.

Blank, Rebecca M. (1989): Analyzing the Length of Welfare Spells, Journal of Public Economics, 39, 245-273.

Boss, Alfred (2002): Sozialhilfe, Lohnabstand und Leistungsanreize. Empirische Analyse für Haushaltstypen und Branchen in West- und Ostdeutschland. Kieler Studien 318. Berlin

Blundell, Richard and Thomas MaCurdy (1999), Labor Supply: A Review of Alternative Approaches. In: Orley Ashenfelter und David Card (eds.), Handbook of Labor Economics, Vol. 3A. Amsterdam, 1559-1591.

Breuer, Wilhelm and Dietrich Engels (2003): Grundinformationen und Daten zur Sozialhilfe. Im Auftrag des Bundesministeriums für Gesundheit und Soziale Sicherung.

Devine, Theresa J. and Nicholas M. Kiefer (1991): Empirical Labor Economics. The Search Approach. Oxford: Oxford University Press.

Engels, Dietrich (2001): Abstand zwischen Sozialhilfe und unteren Arbeitnehmereinkommen: Neue Ergebnisse zu einer alten Kontroverse, Sozialer Forschritt, 50, 56-62.

Fortin, Bernard, Guy Lacroix and Simon Drolet (2004): Welfare benefits and the duration of welfare spells: evidence from a natural experiment in Canada, Journal of Public Economics, 88, 1495-1520.

Gangl, Markus (1998): Sozialhilfebezug und Arbeitsmarktverhalten. Eine Längsschnittanalyse der Übergänge aus der Sozialhilfe in den Arbeitsmarkt, Zeitschrift für Soziologie, 27, 212-232.

Gebauer, Ronald, Hanna Petschauer and Georg Vobruba (2002): Wer sitzt in der Armutsfalls? Selbstbehauptung zwischen Sozialhilfe und Arbeitsmarkt. Berlin: Edition Sigma.

Gittleman, Maury (2001): Declining Caseloads: What Do the Dynamics of Welfare Participation Reveal? Industrial Relations, 40, 537-570.

Hahlen, Johann (2002): Entwicklungen des deutschen Sozialstaates - Daten der amtlichen Statistik, Wirtschaft und Statistik, 12/2002, 1044-1055.

Han, Aaron, and Jerry A. Hausman (1990), Flexible Parametric Estimation of Duration and Competing Risk Models, Journal of Applied Econometrics, 5, 1-28.

Haustein, Thomas and Sascha Krieger (2004): Ergebnisse der Sozialhilfe- und Asylbewerberleistungsstatistik 2002, Wirtschaft und Statistik, 2/2004, 192-208.

Hoynes, Hilary and Thomas MaCurdy (1994): Has the Decline in Benefits Shortened Welfare Spells? The American Economic Review, 84, 43-48.

Jenkins, Stephen P. (2004): Independent competing risks models for interval-censored survival time data. Unpublished Paper, ISER, University of Essex

Kayser, Hilke and Joachim Frick (2001): Take It or Leave It: (Non-)Take-Up Behavior of Social Assistance in Germany, Schmollers Jahrbuch 121, 27-58. 
Meyer, Bruce D. (1990), Unemployment Insurance and Unemployment Spells, Econometrica, 58, 757-782.

Moffitt, Robert (1992): Incentive Effects of the U.S. Welfare System: A Review, Journal of Economic Literature, 30, 1-61.

Moffitt, Robert (2002): Welfare Programs and Labor Supply. In: A. Auerbach and M. Feldstein (eds.), Handbook of Public Economics, Vol. 4, Amsterdam: Elsevier Science, 2393-2430.

Narendranathan, Wiji, and Mark .B. Stewart (1993a): How Does the Benefit Effect Vary as Unemployment Spells Lengthen?, Journal of Applied Econometrics, 8, 361381.

Narendranathan, Wiji, and Mark .B. Stewart (1993b): Modeling the Probability of Leaving Unemployment: Competing Risks Models with Flexible Base-line Hazards, Applied Statistics, 42, 63-83.

Ochel, Wolfgang (2003): Welfare to Work in the U.S.: A Model for Germany? Finanzarchiv, 59, 91-119.

Riphahn, Regina T. (1999): Why Did Social Assistance Dependence Increase? - The Dynamics of Social Assistance Dependence and Unemployment in Germany, 1999, unpublished Habilitationsschrift, University of Munich.

Riphahn, Regina T. (2001): Rational Poverty or Poor Rationality? The Take-up of Social Assistance Benefits, Review of Income and Wealth, 47, 379-398.

Roed, Knut and Morten Nordberg (2003): Temporary layoffs and the duration of unemployment, Labour Economics, 10, 381-398.

Schupp, Jürgen and Gert G. Wagner (2002): Maintenance of and innovation in long term panel studies: The case of the German Socio-Economic Panel (GSOEP), Allgemeines Statistisches Archiv, 86, 163-175.

Statistisches Jahrbuch 2001. Für die Bundesrepublik Deutschland. Wiesbaden: Statistisches Bundesamt.

Stewart, Jennifer and Martin D. Dooley (1999): The Duration of Spells On Welfare and Off Welfare among Lone Mothers in Ontario, Canadian Public Policy, 25 Supplement 1, S47-S72.

Sueyoshi, Glenn T. (1992), Semiparametric Proportional Hazards Estimation of Competing Risks Models With Time-Varying Covariates, Journal of Econometrics, $51,25-28$.

Voges, Jürgen and Götz Rohwer (1992): Receiving Social Assistance in Germany: Risk and Duration, Journal of European Social Policy, 2, 175-191.

Wilde, Joachim (2003): Why do Recipients of German Social Assistance Opt Out? An Empirical Investigation of Incentives with the Low Income Panel. Jahrbücher für Nationalökonomie und Statistik, 223, 719-742.

Wooldridge, J.M. (2002), Econometric Analysis of Cross Section and Panel Data, Cambridge, London. 


\section{Appendix}

Random effects piecewise exponential model

Assumption: Proportional Hazard Rate Model with two competing risks and bivariate normally distributed unobserved heterogeneity:

$\lambda(t \mid x)=\lambda_{1}\left(t \mid x_{1}\right)+\lambda_{2}\left(t \mid x_{2}\right)$

$\lambda_{1}\left(t \mid x_{1}\right)=\lambda_{01}(t) \exp \left(x_{1} \beta_{1}+\eta_{1}\right)$ and $\lambda_{2}\left(t \mid x_{2}\right)=\lambda_{02}(t) \exp \left(x_{2} \beta_{2}+\eta_{2}\right)$

With the assumption of interval constant covariates $x_{q}$ it follows:

$$
\begin{aligned}
S(j) & =\exp \left(-\int_{0}^{t_{j}} \lambda(\tau) d \tau\right)=\exp \left(-\sum_{k=1}^{j} \int_{t_{k-1}}^{t_{k}} \lambda(\tau) d \tau\right) \\
& =\exp \left(-\sum_{q=1}^{2} \sum_{k=1}^{j} \int_{t_{k-1}}^{t_{k}} \lambda_{0 q}(\tau) \exp \left(x_{q k} \beta_{q}+\eta_{q}\right) d \tau\right) \\
& =\exp \left(-\sum_{q=1}^{2} \sum_{k=1}^{j} \exp \left(x_{q k} \beta_{q}+\gamma_{q k}+\eta_{q}\right)\right) \text { with } \gamma_{q k}=\ln \left(\int_{t_{k-1}}^{t_{k}} \lambda_{0 q}(\tau) d \tau\right)
\end{aligned}
$$

Assuming interval constant baseline transition rates $\lambda_{\text {oqk }}$ the transition probability for a destination state $\mathrm{r}=1,2$ corresponds to:

$$
\begin{aligned}
f_{r}(j) & =\int_{t_{j-1}}^{t_{j}} \lambda_{0 r}(\tau) S(\tau) d \tau=\exp \left(x_{r j} \beta_{r}+\gamma_{r j}+\eta_{r}\right) \int_{t_{j-1}}^{t_{j}} S(j) d \tau \\
& =\exp \left(x_{r j} \beta_{r}+\gamma_{r j}+\eta_{r}\right) \int_{t_{j-1}}^{t_{j}} \exp \left(-\sum_{q=1}^{2}\left(\left(\sum_{k=1}^{j-1} \exp \left(x_{q j} \beta_{q}+\gamma_{q j}+\eta_{q}\right)\right)+\int_{t_{j-1}}^{\tau} \lambda_{0 q}(u) \exp \left(x_{q j} \beta_{q}+\eta_{q}\right) d u\right) d \tau\right. \\
& =\exp \left(x_{r j} \beta_{r}+\gamma_{r j}+\eta_{r}\right) \exp \left(-\sum_{q=1}^{2} \sum_{k=1}^{j-1} \exp \left(x_{q j} \beta_{q}+\gamma_{q j}+\eta_{q}\right)\right) \int_{t_{j-1}}^{t_{j}} \exp \left(-\sum_{q=1}^{2} \exp \left(x_{q j} \beta_{q}+\gamma_{q j}+\eta_{q}\right) \int_{t_{j-1}}^{\tau} d u\right) d \tau \\
& =\exp \left(x_{r j} \beta_{r}+\gamma_{r j}+\eta_{r}\right) \exp \left(-\sum_{q=1}^{2} \sum_{k=1}^{j-1} \exp \left(x_{q j} \beta_{q}+\gamma_{q j}+\eta_{q}\right)\right) \int_{t_{j-1}}^{t_{j}} \exp \left(-\sum_{q=1}^{2}\left(\tau-t_{j-1}\right) \exp \left(x_{q j} \beta_{q}+\gamma_{q j}+\eta_{q}\right)\right) d \tau \\
& =\exp \left(x_{r j} \beta_{r}+\gamma_{r j}+\eta_{r}\right) \exp \left(-\sum_{q=1}^{2} \sum_{k=1}^{j-1} \exp \left(x_{q j} \beta_{q}+\gamma_{q j}+\eta_{q}\right)\right)\left[\frac{-\exp \left(-\sum_{q=1}^{2}\left(\tau-t_{j-1}\right) \exp \left(x_{q j} \beta_{q}+\gamma_{q j}+\eta_{q}\right)\right)}{\sum_{q=1}^{2} \exp \left(x_{q j} \beta_{q}+\gamma_{q j}+\eta_{q}\right)}\right]_{t_{j}}^{t_{j}}
\end{aligned}
$$




$$
\begin{aligned}
& =\frac{\exp \left(x_{r j} \beta_{r}+\gamma_{r j}+\eta_{r}\right)}{\sum_{q=1}^{2} \exp \left(x_{q j} \beta_{q}+\gamma_{q j}+\eta_{q}\right)} \exp \left(-\sum_{q=1}^{2} \sum_{k=1}^{j-1} \exp \left(x_{q j} \beta_{q}+\gamma_{q j}+\eta_{q}\right)\right)\left[1-\exp \left(-\sum_{q=1}^{2} \exp \left(x_{q j} \beta_{q}+\gamma_{q j}+\eta_{q}\right)\right)\right] \\
& =\frac{\exp \left(x_{r j} \beta_{r}+\gamma_{r j}+\eta_{r}\right)}{\sum_{q=1}^{2} \exp \left(x_{q j} \beta_{q}+\gamma_{q j}+\eta_{q}\right)}\left[\exp \left(-\sum_{q=1}^{2} \sum_{k=1}^{j-1} \exp \left(x_{q j} \beta_{q}+\gamma_{q j}+\eta_{q}\right)\right)-\exp \left(-\sum_{q=1}^{2} \sum_{k=1}^{j} \exp \left(x_{q j} \beta_{q}+\gamma_{q j}+\eta_{q}\right)\right)\right] \\
& =\frac{\exp \left(x_{r j} \beta_{r}+\gamma_{r j}+\eta_{r}\right)}{\sum_{q=1}^{2} \exp \left(x_{q j} \beta_{q}+\gamma_{q j}+\eta_{q}\right)}[S(j-1)-S(j)]
\end{aligned}
$$

This leads to a likelihood function which is not separable into destination-specific components because we do not assume that transitions can only occur at the interval boundaries (see Roed and Nordberg 2003 or Jenkins 2004 for similar approaches). Therefore we can not estimate destination specific models separately, even in a model without unobserved heterogeneity.

The Likelihood contribution of a single observation can be written as:

$L\left(\beta, \gamma, \eta_{1}, \eta_{2}\right)=\frac{\exp \left(x_{1 j} \beta_{1}+\gamma_{1 j}+\eta_{1}\right)^{c_{1}} \exp \left(x_{2 j} \beta_{2}+\gamma_{2 j}+\eta_{2}\right)^{c_{2}}}{\exp \left(x_{1 j} \beta_{1}+\gamma_{1 j}+\eta_{1}\right)+\exp \left(x_{2 j} \beta_{2}+\gamma_{2 j}+\eta_{2}\right)^{c}}[c S(j-1)-(2 c-1) S(j)]$

with $c_{1}=\left\{\begin{array}{l}1, \text { in the case of a transition to the destination state } 1 \text { in interval } \mathrm{j} \\ 0, \text { else }\end{array}\right.$

$$
\begin{aligned}
& c_{2}=\left\{\begin{array}{l}
1, \text { in the case of a transition to the destination state } 1 \text { in interval } \mathrm{j} \\
0, \text { else }
\end{array}\right. \\
& c=\max \left(c_{1}, c_{2}\right)
\end{aligned}
$$

The corresponding overall likelihood function is:

$$
L\left(\beta, \gamma, \eta_{1}, \eta_{2}\right)=\prod_{i=1}^{n} \frac{\exp \left(x_{1 j} \beta_{1}+\gamma_{1 j}+\eta_{1}\right)^{c_{1}} \exp \left(x_{2 j} \beta_{2}+\gamma_{2 j}+\eta_{2}\right)^{c_{2}}}{\exp \left(x_{1 j} \beta_{1}+\gamma_{1 j}+\eta_{1}\right)+\exp \left(x_{2 j} \beta_{2}+\gamma_{2 j}+\eta_{2}\right)^{c}}[c S(j-1)-(2 c-1) S(j)]
$$


Table A1:

Wage equations for West Germany

\begin{tabular}{|c|c|c|c|c|}
\hline & \multicolumn{2}{|c|}{ Women } & \multicolumn{2}{|c|}{ Men } \\
\hline & Coefficient & $\begin{array}{l}\text { Robust } \\
\text { std. error }\end{array}$ & Coefficient & $\begin{array}{l}\text { Robust } \\
\text { std. error }\end{array}$ \\
\hline \multicolumn{5}{|l|}{$\underline{\text { Selection }}$} \\
\hline Education in years & 0.042 & 0.003 & -0.003 & 0.003 \\
\hline Age & 0.195 & 0.004 & 0.199 & 0.004 \\
\hline Age squared & -0.003 & 0.000 & -0.003 & 0.000 \\
\hline Foreigner & -0.040 & 0.018 & -0.060 & 0.019 \\
\hline children under 6 & -0.629 & 0.015 & -0.002 & 0.014 \\
\hline partner living in household & -0.311 & 0.017 & 0.262 & 0.018 \\
\hline Schleswig-Holstein & -0.001 & 0.050 & -0.032 & 0.051 \\
\hline Hamburg & 0.121 & 0.062 & 0.158 & 0.066 \\
\hline Niedersachsen & -0.089 & 0.040 & -0.095 & 0.041 \\
\hline Bremen & -0.295 & 0.079 & 0.112 & 0.073 \\
\hline Nordrhein-Westfalen & -0.141 & 0.037 & -0.089 & 0.040 \\
\hline Hessen & 0.040 & 0.041 & 0.047 & 0.042 \\
\hline Rheinland-Pfalz / Saarland & -0.110 & 0.042 & -0.045 & 0.044 \\
\hline Baden-Württemberg & 0.004 & 0.038 & 0.057 & 0.040 \\
\hline Bayern & -0.007 & 0.038 & 0.019 & 0.040 \\
\hline 1992 & 0.039 & 0.029 & -0.021 & 0.032 \\
\hline 1993 & 0.023 & 0.029 & 0.005 & 0.032 \\
\hline 1994 & 0.024 & 0.029 & -0.019 & 0.031 \\
\hline 1995 & -0.000 & 0.029 & 0.004 & 0.032 \\
\hline 1996 & 0.014 & 0.027 & -0.013 & 0.030 \\
\hline 1997 & -0.032 & 0.028 & -0.055 & 0.030 \\
\hline 1998 & -0.008 & 0.028 & -0.056 & 0.030 \\
\hline 1999 & 0.028 & 0.027 & -0.015 & 0.030 \\
\hline Constant & -3.421 & 0.079 & -3.176 & 0.087 \\
\hline \multicolumn{5}{|l|}{ Wage equation } \\
\hline Education in years & 0.069 & 0.002 & 0.064 & 0.001 \\
\hline Age & 0.045 & 0.003 & 0.036 & 0.003 \\
\hline Age squared & -0.001 & 0.000 & -0.000 & 0.000 \\
\hline Absence from the labor market & -0.048 & 0.009 & -0.076 & 0.015 \\
\hline Absence from the labor market squared & -0.001 & 0.003 & -0.001 & 0.007 \\
\hline firm-specific human Capital & 0.018 & 0.001 & 0.010 & 0.001 \\
\hline firm-specific human Capital squared & -0.000 & 0.000 & -0.000 & 0.000 \\
\hline Foreigner & -0.065 & 0.009 & -0.040 & 0.007 \\
\hline Schleswig-Holstein & -0.057 & 0.021 & -0.021 & 0.018 \\
\hline Hamburg & 0.023 & 0.022 & 0.060 & 0.022 \\
\hline Niedersachsen & -0.083 & 0.018 & 0.014 & 0.015 \\
\hline Bremen & -0.081 & 0.030 & -0.018 & 0.028 \\
\hline
\end{tabular}




\begin{tabular}{|c|c|c|c|c|}
\hline Nordrhein-Westfalen & -0.046 & 0.016 & 0.022 & 0.014 \\
\hline Hessen & 0.000 & 0.018 & 0.021 & 0.016 \\
\hline Rheinland-Pfalz / Saarland & -0.044 & 0.018 & -0.002 & 0.015 \\
\hline Baden-Württemberg & 0.000 & 0.016 & 0.057 & 0.015 \\
\hline Bayern & -0.006 & 0.016 & 0.026 & 0.014 \\
\hline 1992 & 0.060 & 0.014 & 0.064 & 0.010 \\
\hline 1993 & 0.110 & 0.015 & 0.111 & 0.010 \\
\hline 1994 & 0.125 & 0.014 & 0.125 & 0.010 \\
\hline 1995 & 0.169 & 0.015 & 0.161 & 0.011 \\
\hline 1996 & 0.190 & 0.013 & 0.187 & 0.010 \\
\hline 1997 & 0.190 & 0.013 & 0.201 & 0.010 \\
\hline 1998 & 0.208 & 0.014 & 0.216 & 0.010 \\
\hline 1999 & 0.190 & 0.013 & 0.210 & 0.010 \\
\hline Constant & 1.156 & 0.062 & 1.552 & 0.075 \\
\hline$\lambda$ & -0.013 & 0.015 & -0.123 & 0.024 \\
\hline Sample Size & \multicolumn{2}{|c|}{30212} & \multicolumn{2}{|c|}{29120} \\
\hline Censored Observations & \multicolumn{2}{|c|}{16715} & \multicolumn{2}{|c|}{11004} \\
\hline Log Pseudo-Likelihood & \multicolumn{2}{|c|}{-23214.94} & \multicolumn{2}{|c|}{-21328.96} \\
\hline
\end{tabular}


Table A2:

Wage equations East Germany

\begin{tabular}{|c|c|c|c|c|}
\hline & \multicolumn{2}{|c|}{ Women } & \multicolumn{2}{|c|}{ Men } \\
\hline & Coefficient & $\begin{array}{c}\text { Robust } \\
\text { std. error }\end{array}$ & Coefficient & $\begin{array}{l}\text { Robust } \\
\text { std. error }\end{array}$ \\
\hline \multicolumn{5}{|l|}{$\underline{\text { Selection }}$} \\
\hline Education in years & 0.062 & 0.005 & 0.013 & 0.005 \\
\hline Age & 0.245 & 0.005 & 0.206 & 0.006 \\
\hline Age squared & -0.003 & 0.000 & -0.003 & 0.000 \\
\hline Foreigner & -0.090 & 0.064 & -0.415 & 0.086 \\
\hline children under 6 & 0.500 & 0.020 & -0.012 & 0.022 \\
\hline partner living in household & 0.068 & 0.023 & 0.170 & 0.028 \\
\hline Sachsen & -0.150 & 0.037 & 0.050 & 0.043 \\
\hline Sachsen-Anhalt & -0.153 & 0.040 & 0.072 & 0.045 \\
\hline Thüringen & -0.171 & 0.040 & 0.067 & 0.046 \\
\hline Mecklenburg-Vorpommern & -0.258 & 0.043 & -0.052 & 0.049 \\
\hline Brandenburg & -0.236 & 0.040 & -0.082 & 0.046 \\
\hline 1992 & -0.169 & 0.035 & -0.143 & 0.041 \\
\hline 1993 & -0.248 & 0.036 & -0.267 & 0.042 \\
\hline 1994 & -0.263 & 0.038 & -0.220 & 0.042 \\
\hline 1995 & -0.245 & 0.038 & -0.174 & 0.042 \\
\hline 1996 & -0.257 & 0.037 & -0.246 & 0.043 \\
\hline 1997 & -0.282 & 0.038 & -0.289 & 0.043 \\
\hline 1998 & -0.308 & 0.038 & -0.331 & 0.044 \\
\hline 1999 & -0.274 & 0.038 & -0.252 & 0.044 \\
\hline Constant & -4.259 & 0.115 & -3.300 & 0.126 \\
\hline \multicolumn{5}{|l|}{ Wage equation } \\
\hline Education in years & 0.078 & 0.002 & 0.059 & 0.001 \\
\hline Age & 0.061 & 0.008 & 0.013 & 0.003 \\
\hline Age squared & -0.001 & 0.000 & -0.000 & 0.000 \\
\hline Absence from the labor market & -0.082 & 0.016 & -0.155 & 0.019 \\
\hline Absence from the labor market squared & 0.001 & 0.005 & 0.008 & 0.010 \\
\hline firm-specific human Capital & 0.016 & 0.002 & 0.000 & 0.001 \\
\hline firm-specific human Capital squared & -0.000 & 0.000 & 0.000 & 0.000 \\
\hline Foreigner & -0.076 & 0.025 & 0.039 & 0.037 \\
\hline Sachsen & -0.206 & 0.017 & -0.195 & 0.016 \\
\hline Sachsen-Anhalt & -0.171 & 0.017 & -0.164 & 0.017 \\
\hline Thüringen & -0.200 & 0.018 & -0.199 & 0.017 \\
\hline Mecklenburg-Vorpommern & -0.127 & 0.020 & -0.132 & 0.018 \\
\hline Brandenburg & -0.157 & 0.019 & -0.141 & 0.017 \\
\hline 1992 & 0.303 & 0.015 & 0.241 & 0.014 \\
\hline 1993 & 0.518 & 0.016 & 0.437 & 0.015 \\
\hline 1994 & 0.628 & 0.016 & 0.562 & 0.014 \\
\hline
\end{tabular}




\begin{tabular}{lllll}
1995 & 0.704 & 0.017 & 0.635 & 0.015 \\
1996 & 0.736 & 0.016 & 0.675 & 0.015 \\
1997 & 0.762 & 0.016 & 0.711 & 0.016 \\
1998 & 0.775 & 0.017 & 0.726 & 0.016 \\
1999 & 0.777 & 0.016 & 0.713 & 0.016 \\
Constant & -0.050 & 0.178 & 1.428 & 0.070 \\
$\lambda$ & 0.190 & 0.047 & -0.019 & 0.012 \\
\hdashline Sample Size & \multicolumn{3}{c}{13851} & \multicolumn{2}{c}{53304} \\
Censored Observations & \multicolumn{3}{c}{-9562} & \multicolumn{3}{c}{-9731.48} \\
Log Pseudo-Likelihood & -10316.27 & \\
\hline
\end{tabular}


Table A3: Discrete-time proportional hazard rate models

\begin{tabular}{|c|c|c|c|c|c|c|c|c|}
\hline \multirow[b]{3}{*}{ Variable } & \multicolumn{4}{|c|}{ Piecewise exponential model } & \multicolumn{4}{|c|}{ Random effects piecewise exponential model } \\
\hline & \multicolumn{2}{|c|}{$\begin{array}{l}\text { Transitions to } \\
\text { Employment }\end{array}$} & \multicolumn{2}{|c|}{ Alternative Transitions } & \multicolumn{2}{|c|}{$\begin{array}{l}\text { Transitions to } \\
\text { Employment }\end{array}$} & \multicolumn{2}{|c|}{ Alternative Transitions } \\
\hline & Coefficient & t-value & Coef. & t-value & Coefficient & t-value & Coef. & t-value \\
\hline 2 years & $-0.41 *$ & -1.91 & $-0.56 * *$ & -1.91 & -0.36 & -1.36 & -0.35 & -1.05 \\
\hline 3 years & -0.35 & -1.07 & $-0.63 *$ & -1.07 & -0.27 & -0.68 & -0.31 & -0.61 \\
\hline 4 years & -0.84 & -1.63 & -0.72 & -1.63 & -0.75 & -1.28 & -0.34 & -0.51 \\
\hline 5 and more years & -1.36 * & -1.88 & -0.92 & -1.88 & -1.25 & -1.56 & -0.49 & -0.61 \\
\hline \multicolumn{9}{|l|}{ Year of observation } \\
\hline 1992 & -0.40 & -0.75 & 0.21 & 0.38 & -0.42 & -0.77 & 0.17 & 0.30 \\
\hline 1993 & -0.10 & -0.21 & 0.26 & 0.49 & -0.10 & -0.19 & 0.21 & 0.37 \\
\hline 1994 & 0.06 & 0.13 & 0.37 & 0.72 & 0.07 & 0.14 & 0.38 & 0.67 \\
\hline 1995 & -0.27 & -0.56 & 0.06 & 0.12 & -0.26 & -0.53 & 0.07 & 0.12 \\
\hline 1996 & -0.44 & -0.86 & 0.34 & 0.66 & -0.43 & -0.83 & 0.34 & 0.59 \\
\hline 1997 & -0.18 & -0.35 & 0.20 & 0.37 & -0.18 & -0.35 & 0.14 & 0.24 \\
\hline 1998 & 0.19 & 0.38 & 0.19 & 0.37 & 0.20 & 0.40 & 0.19 & 0.33 \\
\hline 1999 & $-1.16 * *$ & -2.14 & -0.84 & -1.49 & $-1.17 * *$ & -2.11 & -0.90 & -1.47 \\
\hline Local unemployment rate & -0.05 & -1.51 & -0.05 & -1.26 & -0.05 & -1.46 & -0.04 & -1.06 \\
\hline $\begin{array}{l}\text { At least one adult household member } \\
\text { with vocational training }\end{array}$ & 0.20 & 1.08 & -0.19 & -1.07 & 0.20 & 1.02 & -0.19 & -0.94 \\
\hline $\begin{array}{l}\text { At least one adult household member } \\
\text { with school graduation }\end{array}$ & 0.17 & 0.46 & 0.23 & 0.74 & 0.18 & 0.48 & 0.28 & 0.78 \\
\hline No partner household (female) & $-0.69 * * *$ & -3.86 & 0.17 & 0.96 & $-0.72 * * *$ & -3.55 & 0.21 & 1.02 \\
\hline No partner household (male) & $-0.66 *$ & -1.93 & 0.15 & 0.50 & $-0.69 *$ & -1.88 & 0.19 & 0.52 \\
\hline Adult household member aged $>50$ & $-0.83 * * *$ & -2.88 & -0.42 & -1.62 & $-0.85 * * *$ & -2.83 & -0.50 & -1.60 \\
\hline December dummy & $2.32 * * *$ & 16.09 & $3.03 * * *$ & 19.34 & $2.34 * * *$ & 15.37 & $3.10 * * *$ & 15.92 \\
\hline January dummy & $-1.44 * *$ & -2.01 & -0.55 & -0.92 & $-1.44 * *$ & -2.01 & -0.51 & -0.85 \\
\hline East Germany & $0.75 * *$ & 2.26 & $0.76 * *$ & 2.12 & $0.77 * *$ & 2.23 & $0.82 * *$ & 2.02 \\
\hline Children aged 6 and younger & -0.24 & -1.43 & -0.15 & -0.82 & -0.25 & -1.42 & -0.16 & -0.79 \\
\hline Children aged between 6 and 18 & $0.47 * *$ & 2.58 & 0.11 & 0.56 & $0.48 * *$ & 2.52 & 0.10 & 0.46 \\
\hline Non German adult household member & -0.25 & -1.35 & 0.18 & 1.00 & -0.26 & -1.33 & 0.28 & 1.15 \\
\hline Handicapped adult household member & -0.17 & -0.64 & -0.01 & -0.04 & -0.19 & -0.66 & -0.03 & -0.10 \\
\hline Income Ratio & 0.45 * & 1.95 & 0.40 * & 1.76 & $0.45 *$ & 1.91 & 0.45 & 1.65 \\
\hline Constant & $-3.79 * * *$ & -5.59 & $-4.91 * * *$ & -7.03 & $-3.84 * * *$ & & $-5.28 * * *$ & -5.69 \\
\hline $\operatorname{Ln}\left(\sigma^{2}\right)$ & & & & & -1.08 & -5.40 & -0.28 & 0.69 \\
\hline $\operatorname{CoV}\left(\eta_{1}, \eta_{2}\right)$ & & & & & & & 001 & \\
\hline Log Likelihood & & -14 & 6.31 & & & & 15.93 & \\
\hline
\end{tabular}

579 spells, 7752 months, ${ }^{*}$ significant at the 10 percent level, $* *$ at the 5 percent level, $* * *$ at the 1 percent level. For missing values concerning the handicap and vocational training variables we included additional dummies. Their insignificant coefficients are not reported here. 
Figure A1: Histogram: Ratio between potential net income and the amount of social assistance $(n=8373)$

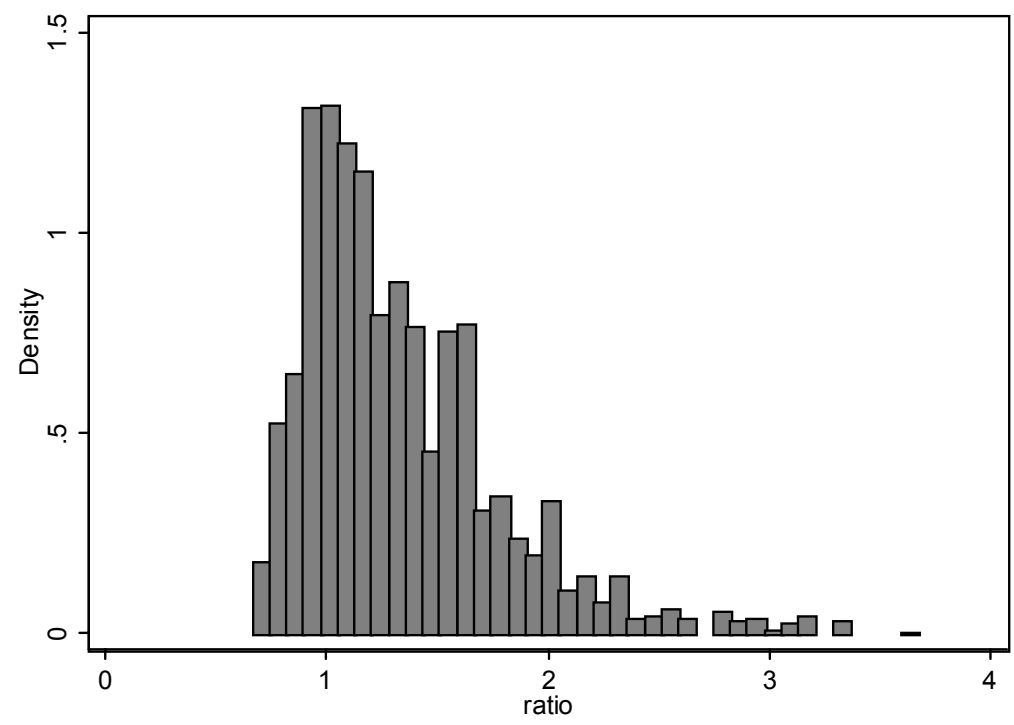

Figure A2: Histogram: Ratio between potential net income and the amount of social assistance, first month of welfare spell, single households $(n=277)$

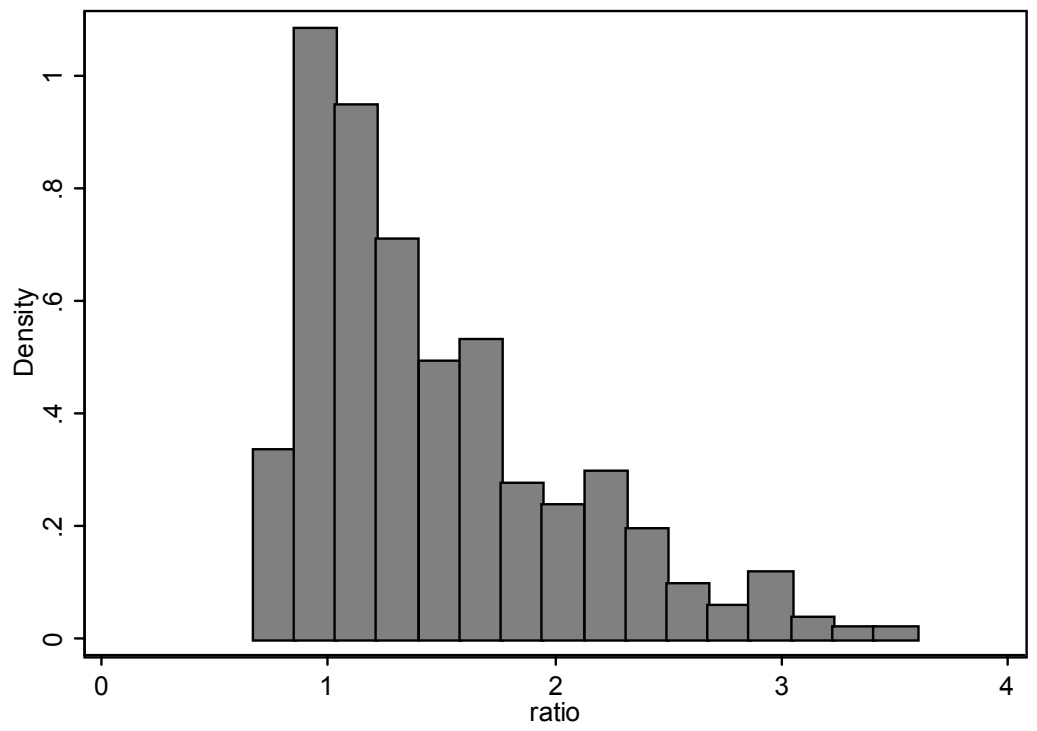


Figure A3: Histogram: Ratio between potential net income and the amount of social assistance, first month of welfare spell, partner households $(n=302)$

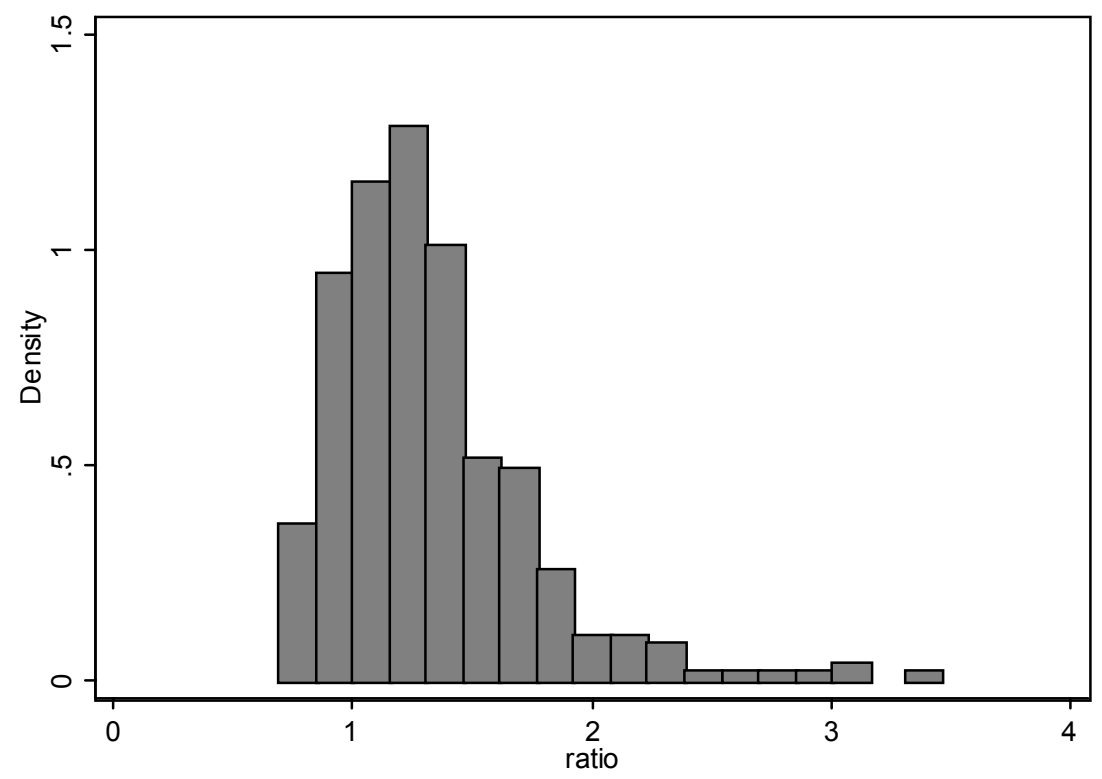

Figure A4: Hazard rates of two households with income ratio 0.5 and 2

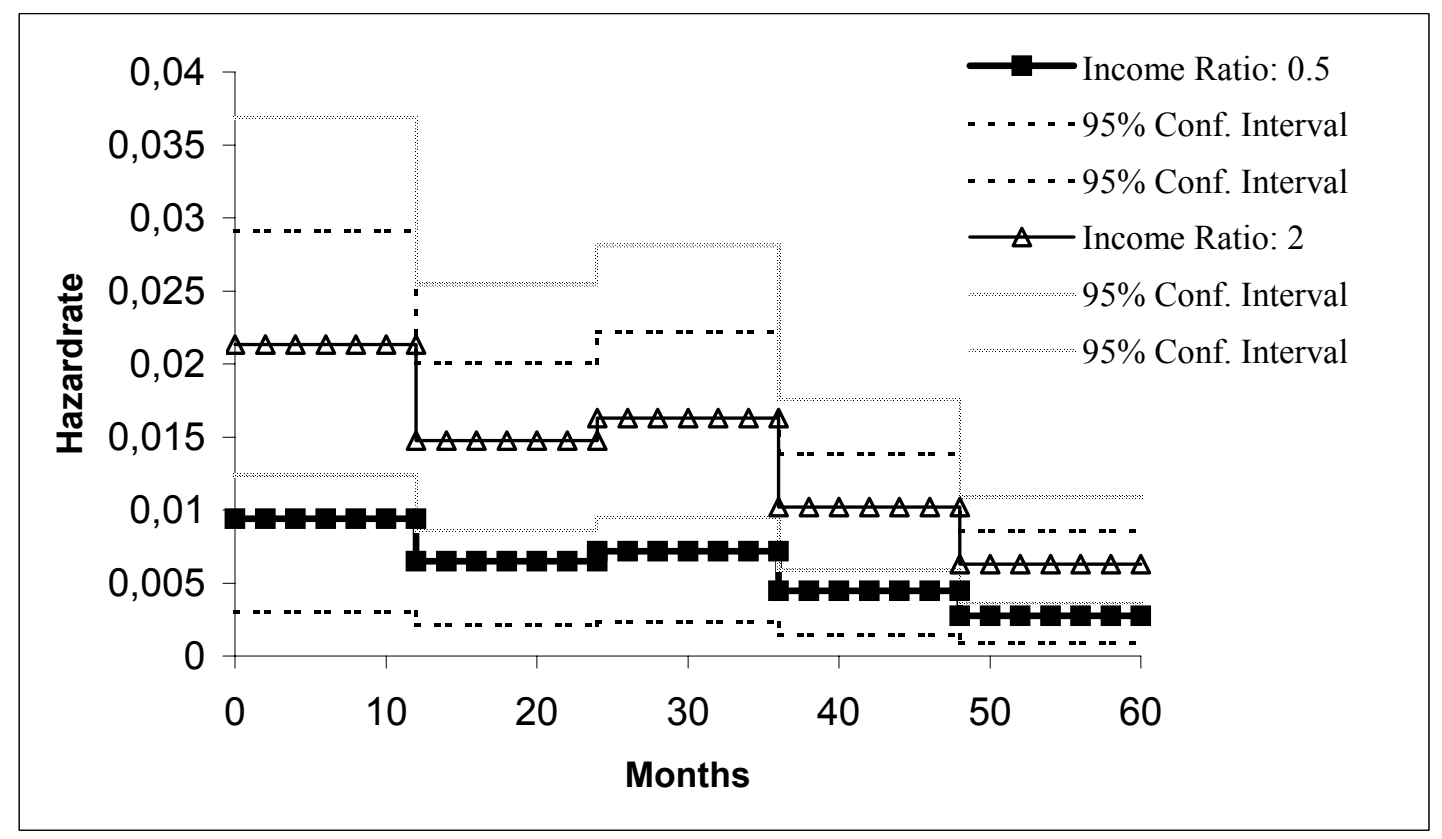

The Hazard rates are calculated for average households, differing only in their income ratios. 